\title{
Opioid-Induced GABA Potentiation after Chronic Morphine Attenuates the Rewarding Effects of Opioids in the Ventral Tegmental Area
}

\author{
Anuradha Madhavan, ${ }^{1}$ Antonello Bonci, ${ }^{1,2}$ and Jennifer L. Whistler ${ }^{1,2}$ \\ ${ }^{1}$ Ernest Gallo Clinic and Research Center, University of California, San Francisco, Emeryville, California 94608, ${ }^{2}$ Department of Neurology, University of \\ California, San Francisco, California 94143-0114
}

\begin{abstract}
GABA transmission in the ventral tegmental area (VTA) is critical for fine tuning the activity of dopamine neurons in response to opioids. However, the precise mechanism by which GABA input shapes opioid reward is poorly understood. We observed a reduction of conditioned place preference for low doses of the opioid [D-Ala2, $N$-MePhe4, Gly5-ol]-enkephalin (DAMGO) and a switch in the functional effects of $\mu$-opioid receptor modulation of GABA postsynaptic currents in the mouse VTA $1 \mathrm{~d}$ after chronic morphine treatment. Specifically, whereas in naive mice DAMGO inhibits GABA postsynaptic currents, GABAergic currents are potentiated by DAMGO after chronic morphine treatment. Importantly, pretreatment with the cAMP signaling inhibitor (R)-adenosine, cyclic $3^{\prime}, 5^{\prime}$-(hydrogenphosphorothioate) triethylammonium both restored DAMGO reward and reversed the DAMGO-mediated potentiation, thereby reestablishing the inhibitory effects of opioids on GABA currents. Thus, a paradoxical bidirectionality in $\mu$-receptor-mediated control of GABA transmission following chronic morphine treatment is a critical mechanism that determines the expression of opioid reward in the VTA.
\end{abstract}

\section{Introduction}

Opioids, which are of great utility as painkillers, are rewarding, a property that may contribute to their propensity to produce physical dependence and addiction. The injection of $\mu$-opioid receptor agonists, such as morphine, heroin, and DAMGO ([D$\mathrm{Ala}^{2}, \mathrm{~N}$-MePhe $\left.{ }^{4}, \mathrm{Gly}-\mathrm{ol}\right]$-enkephalin), into the ventral tegmental area (VTA) induces conditioned place preference (CPP) (Phillips and LePiane, 1980, 1982; Phillips et al., 1983; Spyraki et al., 1983; Bozarth, 1987), identifying the VTA as a locus that mediates the rewarding effects of opioids (Wise, 1989).

In the VTA, GABA interneurons containing $\mu$-receptors innervate the dopaminergic projection neurons (Johnson and North, 1992). Agonist binding to $\mu$-opioid receptors negatively modulates GABA transmission onto dopaminergic neurons, resulting in their disinhibition (Johnson and North, 1992). This GABA-mediated control of dopamine transmission onto target brain regions likely underlies, at least in part, the rewarding properties of opioids (Phillips et al., 1983; Spyraki et al., 1983; Tzschentke, 1998; Fenu et al., 2006). Indeed, intra-VTA infusion of GABA antagonists and agonists modulates reward via both dopamine-dependent and dopamine-independent projections from the VTA (Laviolette and van der Kooy, 2001; Laviolette et al., 2004).

\footnotetext{
Received June 29, 2010; revised Aug. 18, 2010; accepted Aug. 20, 2010.

This work was supported by funds provided by the state of California for medical research on alcohol and substance abuse through the University of California, San Francisco and by the National Institute on Drug Abuse Grants DA015232 and DA019958 (both to J.L.W.).

Correspondence should be addressed to Jennifer L. Whistler, Ernest Gallo Clinic and Research Center, 5858 Horton Street, Suite 200, Emeryville, CA 94608. E-mail: jwhistler@gallo.ucsf.edu.

D0I:10.1523/JNEUROSCI.3366-10.2010

Copyright $\odot 2010$ the authors $\quad$ 0270-6474/10/3014029-07\$15.00/0
}

Chronic opioid exposure causes physical dependence, a behavioral state characterized by withdrawal or distress signs upon acute removal of the drug (Koob et al., 1992). The VTA plays a role in the expression of withdrawal (Baumeister et al., 1989; Stinus et al., 1990; Madhavan et al., 2010). Associated with these changes in behavior, in parallel, chronic morphine exposure also causes synaptic adaptations in the VTA GABA signal, resulting in a compensatory upregulation of GABA release upon drug withdrawal (Bonci and Williams, 1997; Madhavan et al., 2010). In addition, intra-VTA administration of the opioid antagonist naloxone after chronic systemic morphine treatment in mice induces conditioned place aversion (Stinus et al., 1990), demonstrating the importance of the VTA for mediating the negative motivational state associated with withdrawal.

Chronic self-administration of opioids, stimulants, and many other drugs of abuse results in increased intracranial selfstimulation, leading to the view that chronic drug use causes adaptations in reward circuitry that increase the reward threshold of a drug (Kenny et al., 2006; Koob and Le Moal, 2008). However, other studies have found that chronic drug administration may result in reward sensitization, therefore increasing the rewarding capacity of the opioid (Gaiardi et al., 1991; Shippenberg et al., 1996). Thus, the precise mechanism by which opioids shape reward in the VTA during chronic drug use remains unresolved. In particular, how chronic morphine-driven adaptations in GABA transmission in the VTA affect opioid modulation of intra-VTA reward and GABA IPSCs remains unknown. Here, we examined the effects of chronic morphine treatment on the functional and rewarding effects of intraVTA opioids.

\section{Materials and Methods}

Subjects. Electrophysiology was performed on male C57-black/6 mice aged between postnatal d 23 and 28. Conditioned place preference ex- 
periments were conducted in adult (postnatal d 45-50) male C57-black/6 mice, which were surgically cannulated to receive drug infusions in the VTA. All mice were bred in-house and procedures were performed in accordance with Institutional Animal Care and Use Committee guidelines at the Ernest Gallo Clinic and Research Center (Emeryville, CA).

Electrophysiology. The mice were anesthetized with 5\% isoflurane and immediately decapitated using a guillotine. Horizontal brain slices 190 $\mu \mathrm{m}$ thick were cut in ice-cold modified artificial CSF (aCSF) solution. All solutions were saturated with $95 \% \mathrm{O}_{2}-5 \% \mathrm{CO}_{2}$ (carbogen). The composition of the cutting solution was (in $\mathrm{mM}$ ): 85 choline $\mathrm{Cl}, 40 \mathrm{NaCl}, 4 \mathrm{KCl}$, $1.25 \mathrm{NaH}_{2} \mathrm{PO}_{4}, 25 \mathrm{NaHCO}_{3}, 0.5 \mathrm{CaCl}_{2}, 7 \mathrm{MgCl}_{2}, 10$ dextrose, 1 ascorbate, 3 Na pyruvate, and 3 myo-inositol; osmolarity $310-320$. Slices recovered first for $\sim 10-15 \mathrm{~min}$ at $32^{\circ} \mathrm{C}$ in the cutting solution and were later transferred to recording aCSF of the following composition (in $\mathrm{mm}): 125 \mathrm{NaCl}, 2.5 \mathrm{KCl}, 1.25 \mathrm{NaH}_{2} \mathrm{PO}_{4}, 1 \mathrm{MgSO}_{4}, 2 \mathrm{CaCl}_{2}, 25$ dextrose, and $25 \mathrm{NaHCO}_{3}$; osmolarity 295-300. GABA currents were recorded in the presence of DNQX $(10 \mu \mathrm{M})$, strychnine $(10 \mu \mathrm{M})$, CGP $54346(10 \mu \mathrm{M})$, and eticlopride $\left(100 \mathrm{~nm}\right.$ ) to block glutamate, glycine, $\mathrm{GABA}_{\mathrm{b}}$, and dopamine D2 receptors, respectively.

Whole-cell patch-clamp recordings with 3-5 $\mathrm{M} \Omega$ electrodes were made with a Multiclamp 700B amplifier using Clampex 10.0 (Molecular Devices) and Igor Pro 6.0 (Wavemetrics) for data acquisition. The series resistance $\left(R_{\mathrm{s}}\right)$, input resistance $\left(R_{\mathrm{i}}\right)$, and holding current $\left(I_{\text {hold }}\right)$ of all recordings were continuously monitored. Recordings with large deviations in any of these properties were discarded from analysis. VTA neurons included in this study were located medial to the medial terminal nucleus. To record GABA IPSCs, we used an internal solution of the following composition (in mM): $125 \mathrm{KCl}, 10 \mathrm{NaCl}, 1 \mathrm{MgCl}_{2}, 10$ HEPES, 1 EGTA, 2 Na-ATP, 0.6 Na-GTP, and 5 creatine phosphate, pH 7.2-7.4; osmolarity 275-285. Neurons were visualized with an upright microscope equipped with infrared differential interference contrast using Axiovision camera and software (Carl Zeiss Microimaging). aCSF at 30$32^{\circ} \mathrm{C}$ was continuously perfused at $2-3 \mathrm{ml} / \mathrm{min}$ over brain slices. Wholecell voltage-clamp recordings were performed at a holding potential of $-70 \mathrm{mV}$. All cells recorded were first tested for the presence of $I_{\mathrm{h}}$ currents, a cellular marker of dopamine neurons in the VTA (Grace and Onn, 1989).

VTA cannulation surgeries. Male C57-black/6 mice, postnatal d 45-50, were anesthetized with a mixture of ketamine and xylazine, their heads shaved, disinfected, and a $1 \mathrm{~cm}$ incision was cut in the scalp to reveal the skull. Mice were placed in a digital stereotaxic alignment instrument (Model 1900; David Kopf Instruments). The skull was cleaned and leveled in the coronal and sagittal planes using bregma and lambda as reference points. Holes were drilled bilaterally in the skull at the anterior/ posterior (AP) (in reference to bregma) and medial/lateral (ML) coordinates corresponding to VTA (AP, $-3.2 \mathrm{~mm}$; ML, $\pm 0.5 \mathrm{~mm})$ using a $0.3 \mathrm{~mm}$ carbide drill bit. Bilateral cannulae ( 26 gauge bilateral cannulae and 33 gauge injector; Plastics One) measuring dorsal/ventral $-4.7 \mathrm{~mm}$ and ML $\pm 0.5 \mathrm{~mm}$ were inserted to $4.5 \mathrm{~mm}$ below the skull level and secured to the skull using dental acrylic (Geristore kit; Denmat). Bilateral stainless steel dummy cannula and caps were inserted into the guide cannula and remained in place when the guide cannula was not in use. Animals were allowed at least 1 week recovery period before behavioral testing.

After testing for place preference, mice were infused with India ink dye, anesthetized with $5 \%$ isoflurane, and their brains removed and submerged in $4 \%$ formalin dissolved in $0.1 \mathrm{~m}$ PBS overnight. Brains were sectioned at $50 \mu \mathrm{m}$ coronal, mounted, and stained with cresyl violet. Only data from animals with verified correct cannula placement were used in the analysis.

Intra-VTA infusions and CPP assay. For infusions, an injector cannula designed to reach $4.7 \mathrm{~mm}$ below the skull was used. Mice, bilaterally cannulated in the VTA, were injected subcutaneously twice daily (10:00 A.M. and 4:00 P.M.) with morphine $(10 \mathrm{mg} / \mathrm{kg})$ or left untreated for five consecutive days. On d 6, mice were allowed $30 \mathrm{~min}$ access to a twochamber, place-preference apparatus, the chambers distinguishable from each other by the color and floor texture, and the baseline time spent in each chamber was recorded. CPP experiments were conducted $16 \mathrm{~h}$ after the last morphine treatment. Mice with strong initial prefer- ences of $>70 \%$ of total time spent ( $\sim 4 \%$ of the mice) for either chamber were rejected to eliminate any contribution of initial bias to the results. The experiments were counterbalanced for chamber preference and chamber type. Mice were then conditioned to either saline or DAMGO $(5,20$, or $35 \mathrm{ng} / 0.5 \mu \mathrm{l})$ at the rate of $0.1 \mu \mathrm{l} / \mathrm{min}$ followed by $1 \mathrm{~min}$ rest to ensure complete infusion before being put in the chambers. Mice in the chronic morphine group received a maintenance dose of $10 \mathrm{mg} / \mathrm{Kg}$ morphine $4 \mathrm{~h}$ after the CPP experiment. On test day, $1 \mathrm{~d}$ after the last conditioning session, mice were put in the saline-paired side and allowed 30 min free access to both chambers and the time spent in either chamber was recorded.

Data analysis. Data analysis was performed using GraphPad Prizm or Microsoft Excel. Data are represented as mean \pm SEM, unless specified. $\mathrm{T}$ tests (unpaired) or one-way ANOVA was used to compare data for significance.

\section{Results}

Effects of prior morphine exposure on $\boldsymbol{\mu}$-receptor-mediated modulation of GABA IPSCs

We compared the acute effects of the $\mu$-opioid receptor-selective agonist DAMGO on evoked GABA IPSCs in $\mathrm{I}_{\mathrm{h}}^{+}$VTA neurons in morphine-treated $(10 \mathrm{mg} / \mathrm{kg}$ s.c. twice per day for $5 \mathrm{~d}$ ) and untreated mice (Fig. 1A). This protocol of morphine treatment was sufficient to induce naloxone-precipitated morphine withdrawal in wild-type mice in previous studies (Kim et al., 2008; Madhavan et al., 2010), indicating that it is sufficient to induce physical dependence. In slices from mice pretreated with morphine for $5 \mathrm{~d}, 300 \mathrm{~nm}$ DAMGO produced either an inhibition of GABA IPSCs $\left(\Delta \%\right.$ Inhibition $=38.46 \pm 7.43 ; n=12 / 32$ neurons; $t_{(1,15)}=$ $2.53 ; p=0.02)($ Fig. $1 C, F)$ or, more commonly, a potentiation of GABA IPSCs $(\Delta \%$ Potentiation $=89.86 \pm 10.18 ; n=20 / 32$ neurons; $t_{(1,22)}=7.82 ; p<0.0001$ ) (Fig. $\left.1 B, C, F\right) 16-24 \mathrm{~h}$ after the last morphine treatment. When averaged across all neurons (both those inhibited and those potentiated), $300 \mathrm{~nm}$ DAMGO produced a potentiation of GABA IPSCs $(\Delta \%$ Potentiation $=$ $47.58 \pm 11.60 ; n=32 / 32$ neurons) (Fig. $1 C, F)$. This DAMGOinduced potentiation was long-lasting and continued up to a recording time of $80 \mathrm{~min}$ (Fig. $1 \mathrm{~B}$ ). In opioid naive mice, DAMGO (300 nM) always resulted in an inhibition of GABA IPSCs ( $\Delta \%$ Inhibition $=69.35 \pm 5.59 ; n=5 / 5$ neurons) (Fig. $1 E$ ), as previously reported (Johnson and North, 1992). A higher dose of DAMGO $(1 \mu \mathrm{M})$ induced an inhibition of GABA IPSCs in naive conditions $(\Delta \%$ Inhibition $=75.35 \pm 9.94 ; n=7 / 7$ neurons) (Fig. $1 E$ ) and a significantly reduced inhibition $(\Delta \%$ Inhibition $=29.98 \pm 6.50 ; n=9 / 9$ neurons) (Fig. $1 D$ ) but no potentiation after chronic morphine treatment. Therefore, we observed a dose-dependent effect on the ability of DAMGO to potentiate or inhibit GABA IPSCs after chronic morphine treatment.

\section{Chronic morphine reduces the rewarding effects of opioids in the VTA}

We next examined whether these changes in $\mu$-receptor modulation of GABA IPSCs in the VTA affected the rewarding properties of intra-VTA opioids. The CPP assay was used to test the rewarding effects of DAMGO in the VTA of naive and morphinepretreated mice (Fig. 2A,B). Intra-VTA infusion of DAMGO produced a preference to the side paired with drug at the drug doses tested (Fig. 2C) [saline (Sal) vs DAMGO: 5 ng group, $n=6$, $t_{(1,10)}=3.25, p=0.009 ; 20$ ng group, $n=10, t_{(1,18)}=5.59, p<$ $0.0001 ; 35 \mathrm{ng}$ group, $\left.n=9, t_{(1,16)}=2.38, p=0.029\right]$. Difference scores were computed to determine the time spent in the DAMGO-associated chamber (Fig. 2 E) (difference scores $=$ time spent during test (DAMGO - saline) - time spent during base- 
A

A Morphine $10 \mathrm{mg} / \mathrm{Kg} /$ Saline

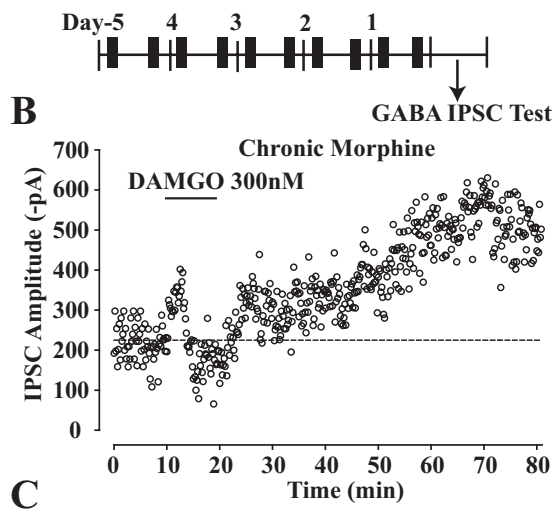

C

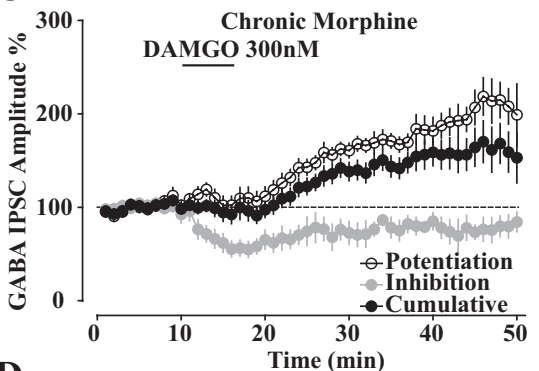

D

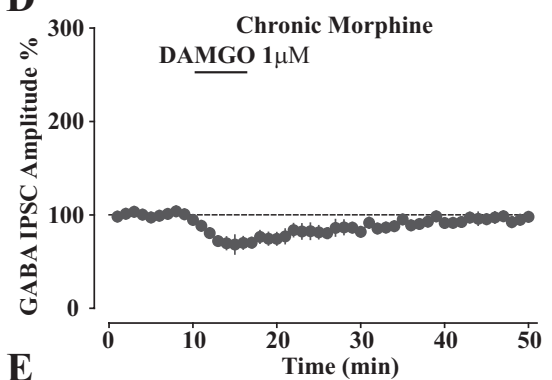

E
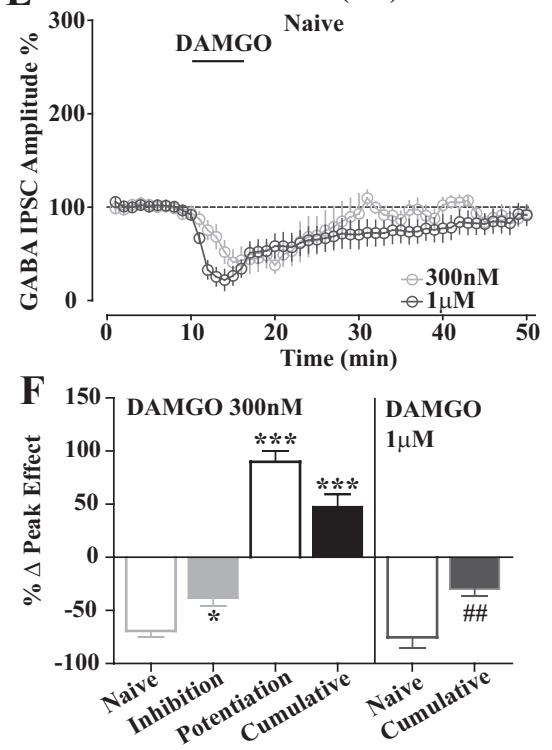

Figure 1. DAMGO induces potentiation or reduced inhibition of GABA IPSCS after chronic morphine. A, Timeline for electrophysiology. $B$, Lasting potentiation of GABA IPSCs induced by DAMGO ( $300 \mathrm{~nm}$ ) in VTA slices taken from chronic morphine-treated mice. C, Average of GABA IPSC responses to DAMGO (300 nM). After chronic morphine treatment, DAMGO induces potentiation ( $n=20 / 32$ neurons) or reduced inhibition ( $n=$ $12 / 32$ neurons) of GABA IPSCs. The cumulative effect is potentiation of GABA IPSCs by DAMG0 after chronic morphine. D, DAMGO $(1 \mu \mathrm{M})$ induces reduced inhibition $(n=9 / 9$ neurons) of GABA IPSCS. E, DAMGO $(300 \mathrm{~nm}, 1 \mu \mathrm{m})$ always induces sizable inhibition of GABA
A

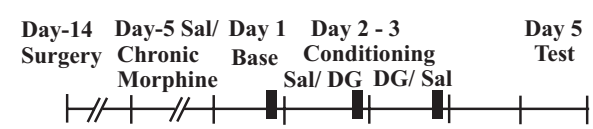

B

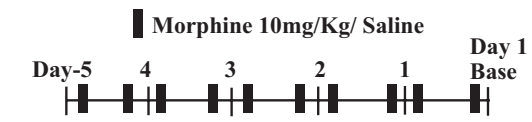

C

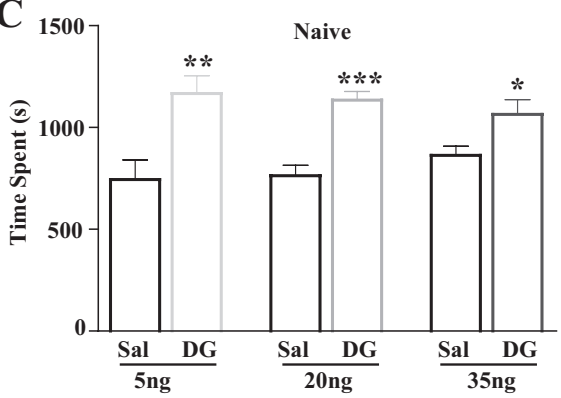

D
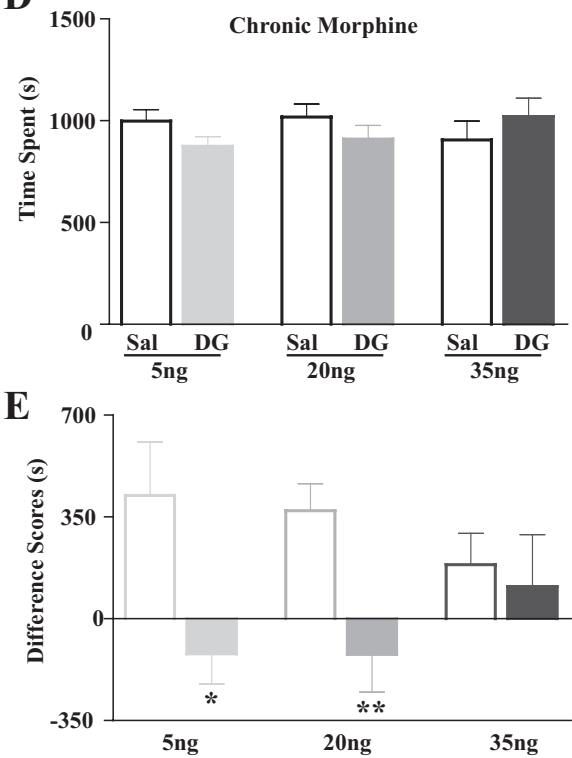

Figure 2. Intra-VTA DAMGO-induced place preference is attenuated after chronic morphine treatment. A, CPP timeline. B, Protocol for morphine injection. C, DAMG0 (5, 20, and $35 \mathrm{ng} / 0.5$ $\mu$ l) injected in the VTA induces place preference by increasing time spent in the DAMGO-paired chamber. D, DAMGO does not induce place preference after chronic morphine treatment. $\boldsymbol{E}$, Difference scores [time (DAMGO) - time (saline) - baseline time (DAMG0) - baseline time (saline)] showing attenuation of place preference at 5 and 20 but not at $35 \mathrm{ng} / 0.5 \mu$ l of DAMGO. DG, DAMG0; Sal, saline. ${ }^{*} p<0.05,{ }^{* *} p<0.01,{ }^{* * *} p<0.0001$.

line (DAMGO - saline); 5 ng group, $424.0 \pm 184.0 \mathrm{~s}, n=6 ; 20 \mathrm{ng}$ group, $371.1 \pm 92.8 \mathrm{~s}, n=10$; 35 ng group, $185.8 \pm 107.6 \mathrm{~s}, n=$ 9). These results show that a single intra-VTA infusion of DAMGO is sufficiently rewarding to induce a place preference.

This paradigm was then used to assess whether prior exposure to morphine, which induced a DAMGO-mediated potentiation

IPSCS in naive conditions ( $n=5 / 5$ and $7 / 7$ neurons). $\boldsymbol{F}$, Bar graph demonstrating the peak change in GABA IPSCs induced by $300 \mathrm{~nm} \mathrm{DAMGO}$ in naive ( $\Delta \%$ Inhibition, $69.35 \pm 5.59 \%$ ), after chronic morphine treatment $(\Delta \%$ Inhibition, $38.46 \pm 7.43 \% ; \Delta \%$ Potentiation, $89.86 \pm$ $10.18 \% ; \Delta \%$ Cumulative, $59.03 \pm 12.70 \%)$, and after $1 \mu \mathrm{m}$ DAMG0 in naive ( $\Delta \%$ Inhibition, $75.35 \pm 9.94 \%$ ) or chronic morphine-treated slices ( $\Delta \%$ Inhibition, $29.98 \pm 6.50 \%) .{ }^{*} p<$ $0.05,{ }^{\# \#} p<0.01,{ }^{* * *} p<0.0001$. 
of GABA IPSC responses in the VTA, caused a change in the rewarding effects of DAMGO. Indeed, DAMGO did not produce a significant place preference in mice pretreated with morphine (all groups, $F_{(1,5)}=0.74, p=0.596$ ) (Fig. $2 D$ ). Neither the $5 \mathrm{ng}$ nor $20 \mathrm{ng}$ doses of DAMGO that were rewarding in naive mice induced place preference in mice pretreated with morphine [difference scores $=$ time spent during test (DAMGO - saline $)-$ time spent during baseline (DAMGO - saline); difference scores: $5 \mathrm{ng}$ chronic morphine group, $-120.0 \pm 104.8 \mathrm{~s}, n=7, t_{(1,11)}=$ $2.67, p=0.022 ; 20 \mathrm{ng}$ of chronic morphine group, $-122.5 \pm$ $130.2 \mathrm{~s}, n=8, t_{(1,16)}=3.17, p=0.006$ ] (Fig. $\left.2 E\right)$. DAMGO (35 ng) resulted in a variable place preference in the morphinepretreated mice, but no significant differences were observed compared with naive controls (difference scores: $35 \mathrm{ng}$ of chronic morphine group, $111.1 \pm 178.5 \mathrm{~s}, n=9, t_{(1,16)}=0.36, p=0.73$ ) (Fig. 2E). Thus, the altered modulation of GABA IPSCs by DAMGO after chronic morphine treatment results in abolished or highly attenuated intra-VTA DAMGO CPP.

\section{Reduction in the rewarding effects of DAMGO is mediated by cAMP}

Chronic morphine results in an upregulation of cAMP signaling in the VTA (Bonci and Williams, 1997; Nestler, 2004; Madhavan et al., 2010). We therefore examined whether changes in protein kinase signaling mediated by cAMP could underlie the loss of DAMGO reward after chronic morphine exposure. The effect of (R)-adenosine, cyclic 3',5' - (hydrogenphosphorothioate) triethylammonium (RP; 10, 25 and $50 \mathrm{ng} /$ $0.5 \mu \mathrm{l}$ ), a potent and specific competitive inhibitor of the activation of cAMP-dependent protein kinases by cAMP, on the expression of place preference to DAMGO after chronic morphine treatment was tested. Mice treated with chronic morphine were conditioned to intra-VTA DAMGO (20 ng/0.5 $\mu \mathrm{l}$ ) or saline in the absence or presence of RP (Fig. $3 A, B$ ). RP pretreatment had a dose-dependent effect on DAMGO place preference in the morphine-pretreated mice (Fig. $3 C$ ). The lowest dose of $10 \mathrm{ng} / 0.5 \mu \mathrm{l}$ of RP did not significantly affect the rewarding properties of DAMGO (time spent: Sal + RP10, $974.8 \pm 134.3 \mathrm{~s}, n=6$; DAMGO + RP10, $964.8 \pm 109.7 \mathrm{~s}, n=$ $6 ; t_{(1,10)}=0.057 ; p=0.96$ ) (Fig. $3 C$ ). At $25 \mathrm{ng} / 0.5 \mu \mathrm{l}, \mathrm{RP}$ significantly enhanced the rewarding properties of DAMGO (time spent: Sal + RP25, $723.0 \pm 128.3 \mathrm{~s}, n=6$; DAMGO + $\mathrm{RP} 25,1243.0 \pm 91.2 \mathrm{~s}, n=6 ; t_{(1,10)}=3.3 ; p=0.008$ ) (Fig. $3 C$ ). As the dose of RP was increased to $50 \mathrm{ng} / 0.5 \mu \mathrm{l}$, the reward was smaller (time spent: Sal + RP50, 946.1 $\pm 124.8 \mathrm{~s}, n=6$; DAMGO + RP50: $1051.0 \pm 104.4 \mathrm{~s}, n=6 ; t_{(1,10)}=0.65 ; p=0.53$ ) (Fig. 3C).

$\mathrm{RP}$, at the concentrations in which it induces place preference in morphine-pretreated mice ( 25 and $50 \mathrm{ng} / 0.5 \mu \mathrm{l}$ ), was not itself rewarding (time spent: Sal, $935.0 \pm 102.7 \mathrm{~s}$; RP25, $1001.0 \pm 98.9 \mathrm{~s}, n=6, t_{(1,10)}=0.46, p=0.65$; Sal, $994.2 \pm$ $130.5 \mathrm{~s}$; RP50, $\left.980.6 \pm 146.5 \mathrm{~s}, n=6, t_{(1,10)}=0.069, p=0.95\right)$ (Fig. 3D) when infused in the VTA. These data suggest that the attenuation of rewarding properties of DAMGO in chronic morphine-treated mice is likely due to adaptive changes in cAMP signaling.

\section{DAMGO-mediated GABA IPSC potentiation is dependent on CAMP}

We next examined whether the GABA current potentiation induced by DAMGO after chronic morphine treatment was mediated by adaptive changes in the cAMP-driven signaling cascade. As above, mice were treated with morphine for $5 \mathrm{~d}$ and, $24 \mathrm{~h}$ after the last morphine exposure, VTA slices were
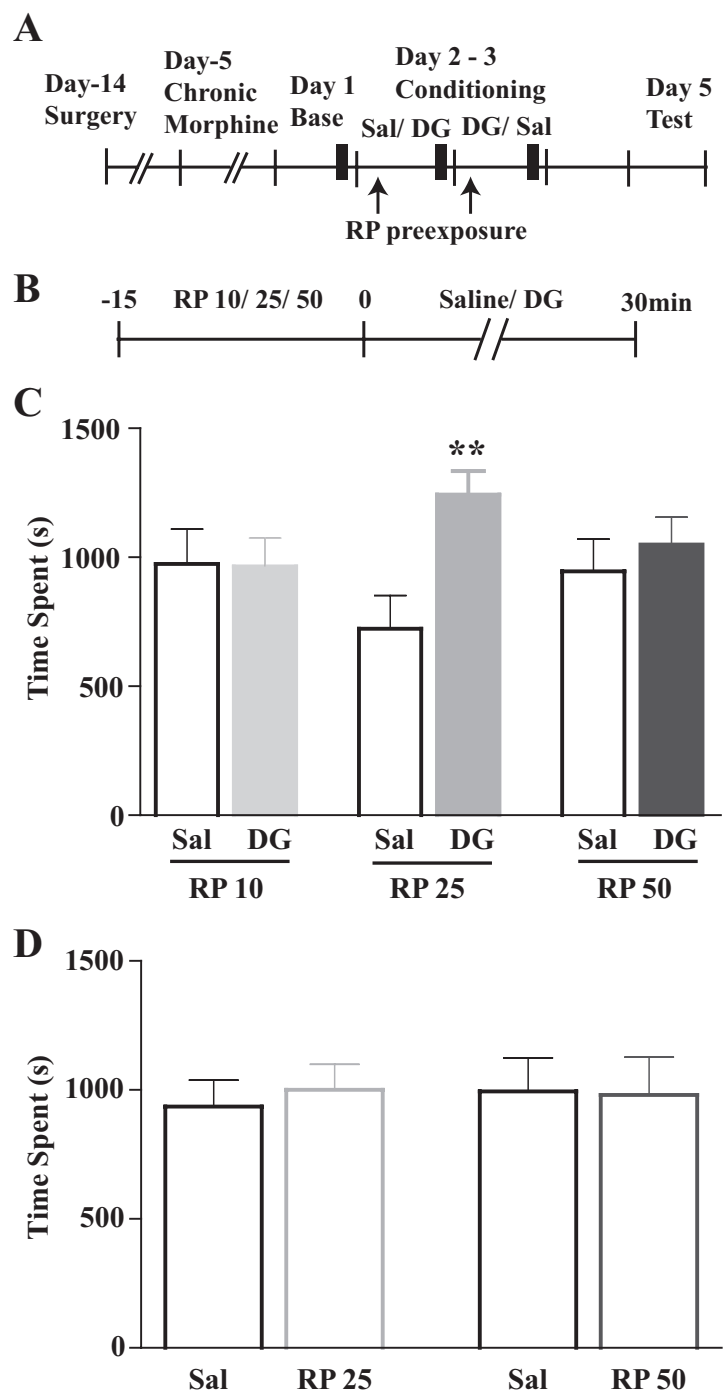

Figure 3. Inhibition of CAMP-dependent protein kinase signaling reverses loss of place preference to DAMGO after chronic morphine treatment. $A$, CPP timeline. $B$, RP pretreatment timeline. $C$, Pretreatment with $\mathrm{RP}$ at $25 \mathrm{ng} / 0.5 \mu \mathrm{l}$ recovers the rewarding effects of DAMGO with an inverted $U$-shaped dose dependence. $\boldsymbol{D}, \mathrm{RP}$ is not significantly more rewarding than saline measured as the time spent in the RP-paired chamber. DG, DAMGO; Sal, saline. ${ }^{* *} p<0.01$.

removed. For each mouse, one VTA slice was treated with DAMGO (Fig. 1) and the other was pretreated with $500 \mathrm{~nm} \mathrm{RP}$ for 15-30 min before recording the effects of DAMGO on GABA IPSCs. RP pretreatment abolished all DAMGOmediated potentiation of GABA IPSCs (Fig. 4C,D) compared with controls where DAMGO induced potentiation (Fig. 1). In addition, DAMGO-mediated inhibition of GABA IPSCs after RP treatment was not significantly different from DAMGO inhibition of GABA currents in naive VTA neurons or RPpreexposed naive VTA neurons $[\Delta \%$ Inhibition (naive) $=69.35 \pm$ 5.6; $n=5 / 5$ neurons; $\Delta \%$ Inhibition $(\mathrm{RP}-$ naive $)=61.38 \pm 8.4 ; n=$ $5 / 5$ neurons; $\Delta \%$ Inhibition $(\mathrm{RP}-$ chronic morphine $)=67.88 \pm 3.6$; $n=6 / 6$ neurons; $F_{(1,2)}=0.49 ; p=0.62$ ) (Fig. $4 B-D$ ). Thus, inhibition of the cAMP pathway has no effect on DAMGO-mediated inhibition of IPSCs in naive mice, but reverses the paradoxical potentiation of GABA IPSCs in slices from mice treated with chronic morphine. Figure 5 shows cannula placement. 
A 【Morphine $10 \mathrm{mg} / \mathrm{Kg} /$ Saline

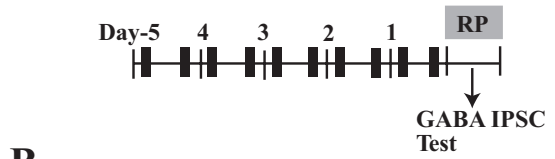

B
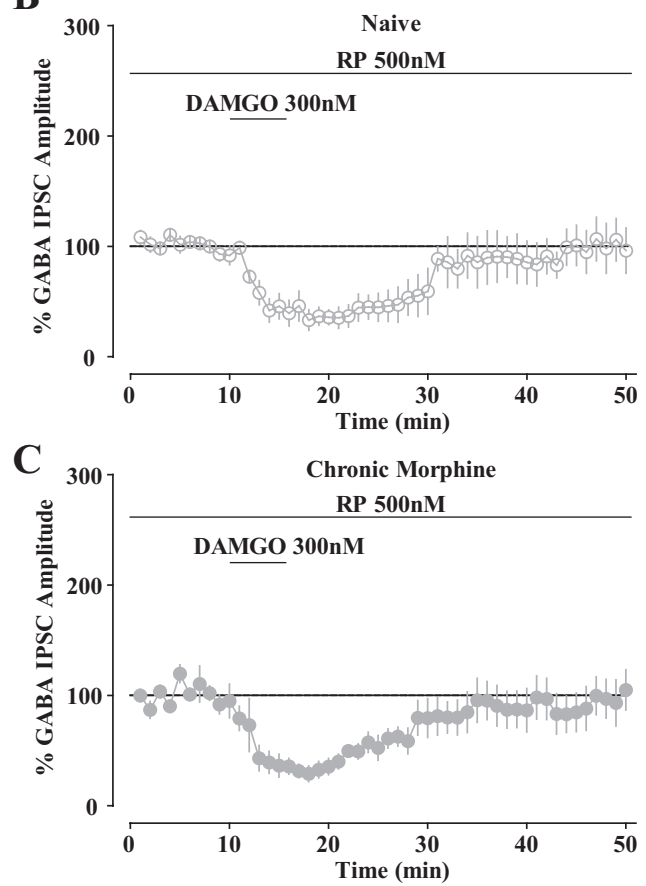

D

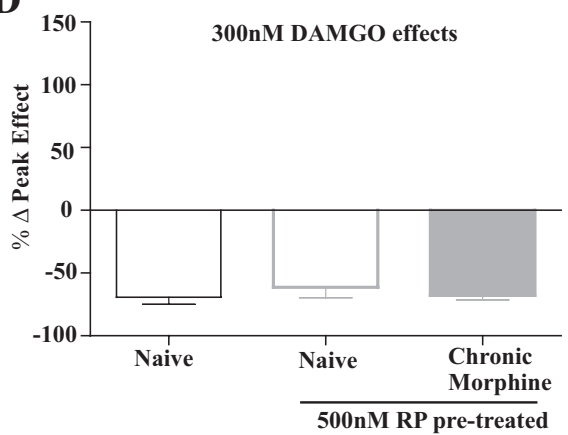

Figure 4. Inhibition of CAMP-dependent protein kinase signaling prevents DAMG0-induced potentiation of GABA after chronic morphine. A, Timeline for electrophysiology after RP pretreatment. $\boldsymbol{B}, \mathrm{RP}(500 \mathrm{~nm})$ pretreatment does not significantly alter DAMGO ( $300 \mathrm{~nm})$ inhibition of GABA IPSCs in naive VTA slices ( $n=5 / 5$ neurons). C, RP ( $500 \mathrm{~nm}$ ) pretreatment results in DAMGO-induced inhibition of GABA IPSC s after chronic morphine treatment ( $n=6 / 6$ neurons). $D$, Bar graph demonstrating the peak change in GABA IPSCs induced by $300 \mathrm{~nm}$ DAMGO in naive mice $(\Delta \%$ Inhibition, $69.35 \pm 5.6 \%)$, after RP pretreatment in naive mice $(\Delta \%$ Inhibition, $61.38 \pm 8.4 \%)$, and after chronic morphine treatment ( $\Delta \%$ Inhibition, $67.88 \pm 3.6 \%)$.

\section{Discussion}

We find that chronic morphine treatment results in a switch in modulation of opioid effects on GABA IPSCs in the VTA. In naive animals, prior evidence indicated that opioids inhibit GABA IPSCs onto neurons in the VTA (Johnson and North, 1992), which we confirmed here. In contrast, we find that chronic morphine treatment results in a novel potentiation of GABA IPSCs by opioids in a majority of neurons, while retaining the inhibitory effects at a reduced efficacy in the remaining neurons. The cumulative results on all neurons indicate that, at low doses, DAMGO enhances GABA IPSCs after chronic
A

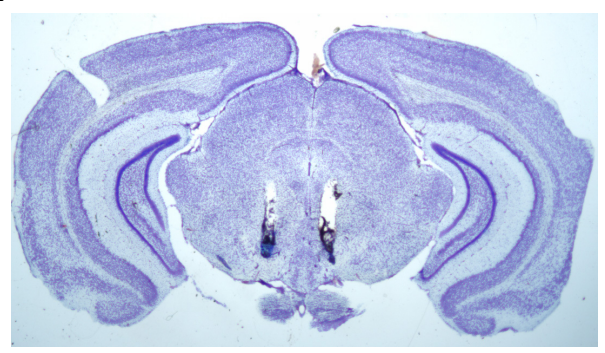

B
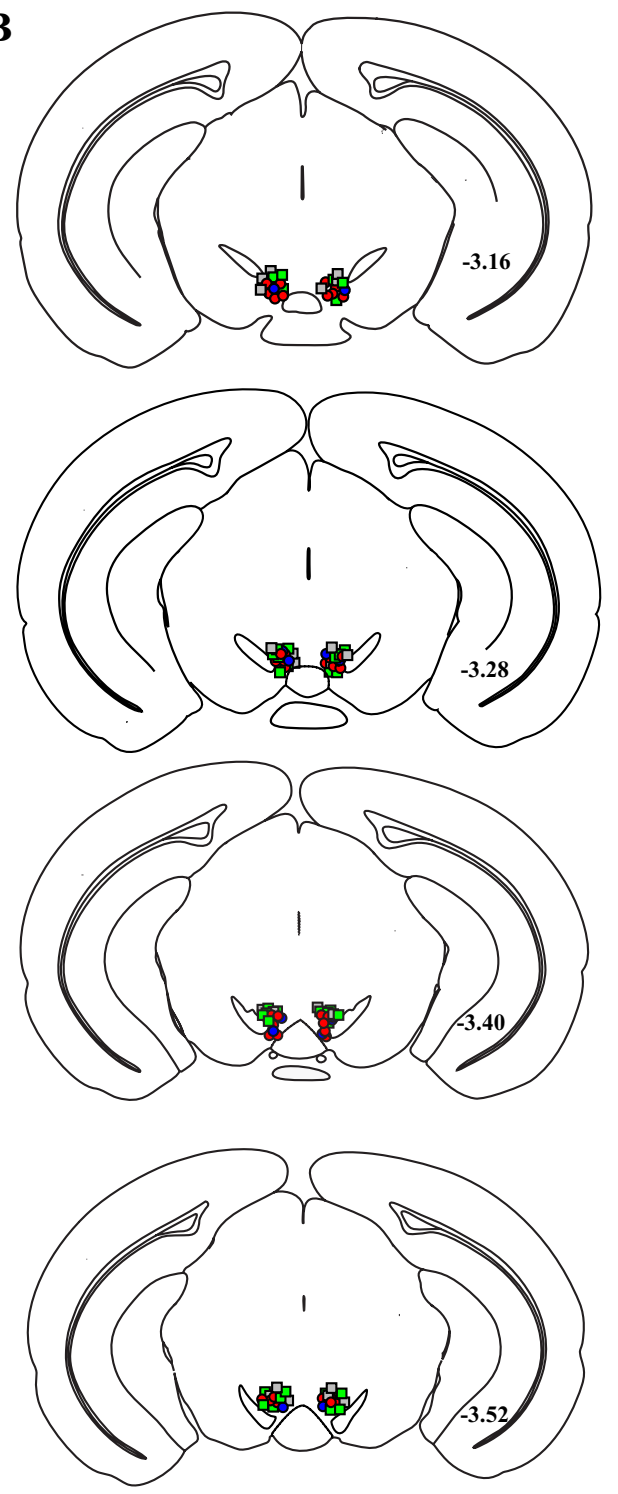

$\begin{array}{cl}\bigcirc & \text { Naive } \\ \square & \text { Chronic morphine } \\ \square & \text { RP Naive } \\ \square & \text { RP Chronic Morphine }\end{array}$

Figure 5. Schematic representation of cannula placements in the VTA. $A$, Nissl-stained coronal VTA section showing cannula placement. $\boldsymbol{B}$, Cannula placements. Coordinates of slides are in relation to bregma.

morphine. Higher doses of DAMGO favor inhibition, although of reduced efficacy compared with naive mice.

In parallel, behaviorally, at the same time point, we confirm that intra-VTA opioids are rewarding in naive animals (Phil- 
lips and LePiane, 1980, 1982). That is, they induce a place preference to the chamber paired with the drug. However, we find that, after chronic morphine treatment, intra-VTA DAMGO is no longer rewarding at doses that produce reward in the naive mice. In addition, we show that both the DAMGO-induced potentiation and the loss of DAMGO reward are dependent on morphine-induced upregulation of cAMP signaling. Specifically, RP, an inhibitor of cAMP-driven protein kinase signaling, restores both opioid inhibition of GABA IPSCs and opioid reward after chronic morphine.

Inhibition of cAMP-driven signaling using RP reduces the increased probability of GABA release in VTA slices during morphine withdrawal (Bonci and Williams, 1997; Madhavan et al., 2010) and also attenuates the expression of withdrawal symptoms during intra-VTA naloxone infusion in morphinedependent mice (Madhavan et al., 2010). Here we find that RP also abolishes DAMGO-induced GABA IPSC potentiation, thereby restoring both the inhibitory effects of DAMGO physiologically and the rewarding effects DAMGO behaviorally in morphine-dependent mice. Thus, cAMP upregulation as a consequence of chronic morphine treatment is likely responsible for the dysregulation of GABA neurotransmission in the VTA after chronic morphine treatment. The effects of cAMP superactivation on GABA release probability are presynaptic (Bonci and Williams, 1997; Madhavan et al., 2010). However, the effects of cAMP superactivation on DAMGO-induced potentiation could also be modulated by postsynaptic cAMPmediated changes in protein kinase $\mathrm{A}$, which have been shown to occur in dopaminergic neurons at least after psychostimulant exposure (Tolliver et al., 1996; Gutlerner et al., 2002; Schilström et al., 2006).

By extension, these changes in GABA plasticity, mediated by cAMP superactivation, are likely also contributing to dysregulation of dopaminergic transmission from the VTA to its target loci, including the nucleus accumbens. In naive mice, opioids in the VTA inhibit GABA release onto dopamine neurons and thereby result in an enhancement of dopamine neurotransmission, a process suggested to contribute to opioid reward (Phillips et al., 1983; Spyraki et al., 1983). Chronic treatment and withdrawal from morphine, cocaine, or alcohol is characterized by a hypodopaminergic state in the nucleus accumbens, which is thought to underlie, at least in part, the negative motivational effect of withdrawal (Acquas et al., 1991; Rossetti et al., 1992; Weiss et al., 1992; Rada et al., 2004). Thus, one might speculate that an increased probability of GABA release from the MOR-expressing cells in the VTA, together with the long-lasting increase in GABA current amplitude induced by DAMGO in the dopamine cells of the VTA, would induce a greater depression of dopaminergic neurotransmission than an increase in GABA release alone. Intriguingly, the potentiation effect of DAMGO is dose-dependent. Specifically, at low doses there is a potentiation of GABA currents, which can be overcome and reversed to inhibition at high doses. These results suggest that we may have identified an electrophysiological substrate that could explain why morphine-dependent animals can show both sensitization and tolerance to drug effects depending on the drug dose and the behavioral paradigm used. In conclusion, we observe a paradoxical shift in the functional effects of opioids, after chronic morphine, on GABAergic currents in the VTA that results in an unexpected loss or devaluation in reward associated with intra-VTA opioids.

\section{References}

Acquas E, Carboni E, Di Chiara G (1991) Profound depression of mesolimbic dopamine release after morphine withdrawal in dependent rats. Eur J Pharmacol 193:133-134.

Baumeister AA, Anticich TG, Hebert G, Hawkins MF, Nagy M (1989) Evidence that physical dependence on morphine is mediated by the ventral midbrain. Neuropharmacology 28:1151-1157.

Bonci A, Williams JT (1997) Increased probability of GABA release during withdrawal from morphine. J Neurosci 17:796-803.

Bozarth MA (1987) Neuroanatomical boundaries of the reward-relevant opiate-receptor field in the ventral tegmental area as mapped by the conditioned place preference method in rats. Brain Res 414:77-84.

Fenu S, Spina L, Rivas E, Longoni R, Di Chiara G (2006) Morphineconditioned single-trial place preference: role of nucleus accumbens shell dopamine receptors in acquisition, but not expression. Psychopharmacology (Berl) 187:143-153.

Gaiardi M, Bartoletti M, Bacchi A, Gubellini C, Costa M, Babbini M (1991) Role of repeated exposure to morphine in determining its affective properties: place and taste conditioning studies in rats. Psychopharmacology (Berl) 103:183-186.

Grace AA, Onn SP (1989) Morphology and electrophysiological properties of immunocytochemically identified rat dopamine neurons recorded in vitro. J Neurosci 9:3463-3481.

Gutlerner JL, Penick EC, Snyder EM, Kauer JA (2002) Novel protein kinase A-dependent long-term depression of excitatory synapses. Neuron 36:921-931.

Johnson SW, North RA (1992) Opioids excite dopamine neurons by hyperpolarization of local interneurons. J Neurosci 12:483-488.

Kenny PJ, Chen SA, Kitamura O, Markou A, Koob GF (2006) Conditioned withdrawal drives heroin consumption and decreases reward sensitivity. J Neurosci 26:5894-5900.

Kim JA, Bartlett S, He L, Nielsen CK, Chang AM, Kharazia V, Waldhoer M, Ou CJ, Taylor S, Ferwerda M, Cado D, Whistler JL (2008) Morphineinduced receptor endocytosis in a novel knockin mouse reduces tolerance and dependence. Curr Biol 18:129-135.

Koob GF, Le Moal M (2008) Review: neurobiological mechanisms for opponent motivational processes in addiction. Philos Trans R Soc Lond B Biol Sci 363:3113-3123.

Koob GF, Maldonado R, Stinus L (1992) Neural substrates of opiate withdrawal. Trends Neurosci 15:186-191.

Laviolette SR, van der Kooy D (2001) GABA(A) receptors in the ventral tegmental area control bidirectional reward signalling between dopaminergic and non-dopaminergic neural motivational systems. Eur J Neurosci 13:1009-1015.

Laviolette SR, Gallegos RA, Henriksen SJ, van der Kooy D (2004) Opiate state controls bi-directional reward signaling via GABAA receptors in the ventral tegmental area. Nat Neurosci 7:160-169.

Madhavan A, He L, Stuber GD, Bonci A, Whistler JL (2010) Micro-opioid receptor endocytosis prevents adaptations in ventral tegmental area GABA transmission induced during naloxone-precipitated morphine withdrawal. J Neurosci 30:3276-3286.

Nestler EJ (2004) Historical review: molecular and cellular mechanisms of opiate and cocaine addiction. Trends Pharmacol Sci 25:210-218.

Phillips AG, LePiane FG (1980) Reinforcing effects of morphine microinjection into the ventral tegmental area. Pharmacol Biochem Behav 12:965-968.

Phillips AG, LePiane FG (1982) Reward produced by microinjection of (DAla2),Met5-enkephalinamide into the ventral tegmental area. Behav Brain Res 5:225-229.

Phillips AG, LePiane FG, Fibiger HC (1983) Dopaminergic mediation of reward produced by direct injection of enkephalin into the ventral tegmental area of the rat. Life Sci 33:2505-2511.

Rada P, Johnson DF, Lewis MJ, Hoebel BG (2004) In alcohol-treated rats, naloxone decreases extracellular dopamine and increases acetylcholine in the nucleus accumbens: evidence of opioid withdrawal. Pharmacol Biochem Behav 79:599-605.

Rossetti ZL, Melis F, Carboni S, Gessa GL (1992) Dramatic depletion of mesolimbic extracellular dopamine after withdrawal from morphine, alcohol or cocaine: a common neurochemical substrate for drug dependence. Ann N Y Acad Sci 654:513-516.

Schilström B, Yaka R, Argilli E, Suvarna N, Schumann J, Chen BT, Carman M, Singh V, Mailliard WS, Ron D, Bonci A (2006) Cocaine enhances 
NMDA receptor-mediated currents in ventral tegmental area cells via dopamine D5 receptor-dependent redistribution of NMDA receptors. J Neurosci 26:8549-8558.

Shippenberg TS, Heidbreder C, Lefevour A (1996) Sensitization to the conditioned rewarding effects of morphine: pharmacology and temporal characteristics. Eur J Pharmacol 299:33-39.

Spyraki C, Fibiger HC, Phillips AG (1983) Attenuation of heroin reward in rats by disruption of the mesolimbic dopamine system. Psychopharmacology (Berl) 79:278-283.

Stinus L, Le Moal M, Koob GF (1990) Nucleus accumbens and amygdala are possible substrates for the aversive stimulus effects of opiate withdrawal. Neuroscience 37:767-773.
Tolliver BK, Ho LB, Reid MS, Berger SP (1996) Evidence for involvement of ventral tegmental area cAMP systems in behavioral sensitization to psychostimulants. J Pharmacol Exp Ther 278:411-420.

Tzschentke TM (1998) Measuring reward with the conditioned place preference paradigm: a comprehensive review of drug effects, recent progress and new issues. Prog Neurobiol 56:613-672.

Weiss F, Markou A, Lorang MT, Koob GF (1992) Basal extracellular dopamine levels in the nucleus accumbens are decreased during cocaine withdrawal after unlimited-access self-administration. Brain Res 593:314318.

Wise RA (1989) Opiate reward: sites and substrates. Neurosci Biobehav Rev 13:129-133. 